\title{
Varenicline and evaluated outcomes in smoking cessation programmes
}

\author{
P. Santus, L. Bassi, A. Airoldi, F. Giovannelli, D. Radovanovic
}

ABSTRACT: Varenicline and evaluated outcomes in smoking cessation programmes. P. Santus, L. Bassi, A. Airoldi, F. Giovannelli, D. Radovanovic.

The morbidity and mortality rates attributed to smoking are substantial and cigarette smoke remains the first preventable cause of premature death worldwide. Despite the knowledge of the adverse consequences of smoking, many smokers struggle to quit. Cigarette smoking is the primary cause of chronic obstructive pulmonary disease, and smoking cessation represents the most effective way of stopping its progression. Varenicline is one of the first-line smoking cessation aids recommended in many Clinical Practice Guidelines and its efficacy and safety have been demonstrated in several clinical trials. Varenicline has a unique mechanism of action and clinical trials support its use as an effective and generally well-tolerated therapy.

This article reviews the clinical pharmacological trials on smoking cessation published in recent years on varenicline, with particular attention to the outcomes used in the studies. MedLine, the Cochrane database and Embase were evaluated.

Almost all the trials have, as a primary endpoint, the abstinence from cigarettes at 9-12 weeks of treatment. Only one study considers lung function spirometric changes as a secondary endpoint. No study has evaluated lung function. This marker could be very important as a way of evaluating, objectively, an improvement in lung function, which correlates also with subjective parameters, as dyspnea and fatigue.

Monaldi Arch Chest Dis 2013; 79: 1, 20-26.

Keywords: Smoking cessation, Varenicline, Tobacco, Smoking, Outcomes.

Università degli Studi di Milano, Dipartimento di Scienze della Salute, Pneumologia Riabilitativa, Fondazione Salvatore Maugeri, Istituto Scientifico di Milano, IRCCS, Milano, Italy.

Correspondence: Pierachille Santus, Università degli Studi di Milano, Dipartimento di Scienze della Salute, Pneumologia Riabilitativa, Fondazione Salvatore Maugeri, Istituto Scientifico di Milano, IRCCS, Via Camaldoli 64, 20138 Milano, Italy; e-mail: pierachille.santus@unimi.it

\section{Introduction}

\section{Epidemiology of cigarettes smoking}

Tobacco use is widely considered the most preventable cause of illness and death and its worldwide use causes more than 5 million deaths per year and if the current trends in the use of tobacco will continue, it will cause 8 million deaths per year by $2030[1,2]$. It must also be underlined that also exposure to environmental tobacco smoke results in an estimated 49,000 deaths every year [2,3]. A recent experience reported that prevalence of smokers in general population is $26 \%$ with the same distribution in all age classes [4].

The numerous harmful health consequences of smoking are represented by cancer, with particular attention to: the lung, oral cavity, oesophagus, stomach and larynges; the cardiovascular system. Tobacco use is also implicated in pathophysiological process that interesting gastrointestinal system (decreased appetite, increase insulin resistance, peptic ulcer, etc.); respiratory system (bronchitis, chronic obstructive pulmonary disease, chronic cough, dyspnea, idiopathic pulmonary fibrosis, etc.); reproductive effects (fertility, low birth weight, pregnancy complications, etc.); muscu- loskeletal (decreased bone mineral density, increased risk for fractures, increased spinal disk disease); mental health and psychosocial status [5-11, $3]$. For these reasons it is necessary to convince the population of smokers to stop smoking, because are also known a number of beneficial effects on various body systems. First of all, numerous studies have focused on the strict correlation between smoking cessation and a reduction of central blood pression and arterial stiffness [11]. Smoking cessation produces effects inflammatory processes and mucosal on lung function. In fact a reduction in the number of alveolar macrophages and polymorphonuclear in BAL fluid after 6 months of smoking cessation, which is also dependent from smoking history was also observed [12-15].

For all these reasons stopping smoking is the first therapeutical and principal aim in treating subjects with respiratory diseases and, with this in mind, a lot of strategies can be adopted, going from pharmacological approaches to psychological support. So the purpose of this review is to perform a brief summary of the possible approaches for smoking cessation with more attention on varenicline, analysing the outcomes evaluated in various studies published in the last years in the scientific literature. 
Current therapies for smoking cessation

\section{Pharmacological treatments for tobacco addiction}

Seven medications for smoking cessation are currently approved by US Food and Drug Administration (FDA): five nicotine replacement therapies (NRTs) as nicotine patch, gum, lozenge, nasal spray and inhaler, and two other medications with a different mechanism of action: bupropion and varenicline [16].

Bupropion, an atypical antidepressant, is approved for treatment of smoking cessation. In preclinical studies bupropion, reduced nicotine's rewarding effects and attenuated nicotine withdrawal symptoms. Its mechanism of action is thought to be mediated by its ability to block the reuptake of norepinephrine (NE) and dopamine (DA) in the mesolimbic system and nucleus accumbens, a key area for nicotine reinforcement. Additionally, bupropion antagonizes brain nicotinic receptors and blocks the reinforcing effects of nicotine. Following oral administration, bupropion is metabolised extensively in the liver and excreted through the kidneys with a half-life of about 20 hours [17].

A new drug, which was approved by FDA in 2006 is varenicline. It is a partial agonist for the $\alpha 4 \beta 2$ subtype of nicotinic acetylcholine receptors (nAChRs), which are associated with the addictive effects of nicotine. Varenicline is also a full agonist at the $\alpha 7 \mathrm{nAChR}$. In smokers, varenicline attenuates the subjective rewarding responses and heart rate increases induced by intravenous nicotine; verenicline also improves tobacco withdrawal symptoms, mood, and cognitive performance in abstinent smokers [18]. All these effects may contribute to varenicline's efficacy for smoking cessation.

\section{Behavioural treatments}

In clinical settings, health care professionals typically spend limited time on solving tobacco addiction, because of the huge amount of clinical duties they are involved in. However, even a 3minute counselling session performed by a physician can increase the likelihood of prolonged abstinence (OR, 1.3) compared with no counseling. A recent meta-analysis of 50 randomised behavioural treatments for smoking cessation concluded that telephone counseling, group treatment, and individual treatments all seem to increase the chances of quitting the smoking habit [19].

\section{New perspectives: vaccines}

Since approved treatment options, combined with intensive counselling, guarantee only a longterm continuous abstinence rates that rarely exceed $30 \%$, and patient adherence to treatment is modest, new treatment options are needed. Vaccination against nicotine is an intriguing novel therapeutic approach to treat nicotine addiction. In fact, by preventing the passage of nicotine into the brain, anti- bodies might abolish the rewarding properties of smoking. Animal studies indicate that antibodies profoundly change the pharmacokinetics of the drug and can interfere with nicotine self-administration. However, in recent phase I/II trials and one unpublished phase III trial, these findings were not fully replicated. So treatment of dependent smokers cannot be reduced to a course of vaccine injections but needs to acknowledge the complex pharmacological and behavioural aspects of smoking [20].

\section{Brief focus on varenicline}

\section{Mechanism of action}

The pharmacologic actions of nicotine in the brain, including nicotine's dependence-producing properties, are mediated by the nAChRs, predominantly the a4b2 nicotinic receptor [21].

The pleasurable effects of nicotine are mediated by the mesolimbic dopaminergic system that consists of ventral tegmental area neurons which project into the nucleus accumbens and prefrontal cortex $[22,23]$. The release of dopamine in the nucleus accumbens is a key component of the pleasurable and rewarding effects of nicotine [24,25].

The partial agonist activity of varenicline at the $\alpha 4 \beta 2 \mathrm{nAChR}$ promotes a sustained, low level of dopamine release, which reduces withdrawal symptoms. Through its higher affinity, lower efficacy, and relatively long half-life compared with nicotine, varenicline is able to prevent nicotine from occupying and activating the $\alpha 4 \beta 2 \mathrm{nAChRs}$ during a smoking cessation relapse. In this way varenicline acts functionally as an antagonist at the $\alpha 4 \beta 2$ neuronal $\mathrm{nAChR}$, and has the potential to inhibit the immediate rewarding effects of nicotine and reduce smoking satisfaction $[26,27]$.

\section{Adverse events}

The most commonly reported adverse events in varenicline treated subjects are nausea, abnormal dreams, insomnia, taste perversion, flatulence, dyspepsia, constipation and headache [18]. Whilst risks of neuropsychiatric adverse events due to varenicline have already been reported in a polled analysis [28], the likelihood of major gastrointestinal adverse effects (such as nausea, constipation and flatulence) during maintenance phase lacks precise documentation [29].

Singh et al meta-analysis showed a significantly increased risk of serious, although not prespecified, adverse cardiovascular events associated with varenicline compared with placebo and the authors concluded that clinicians should carefully balance this risk against the known benefits of the drug on smoking cessation [30]. On the other hand, a more recent meta-analysis by Prochaska better defined what the authors mean with "cardiovascular adverse event", including any ischaemic or arrhythmic adverse cardiovascular event like myocardial infarction, unstable angina, coronary revascularisation, coronary artery disease, arrhythmias, transient ischaemic attacks, stroke, sudden 
death or cardiovascular related death, or congestive heart failure [31].

\section{Selection criteria}

We conducted a MEDLINE using the keywords "varenicline" and "smoking cessation". We concentrated the attention only on varenicline, compared with placebo or other pharmachological approaches, because it is the last and the most efficient drug on the market.

Of the resulting 622 articles, 533 had been published in the last five years. These papers could be classified as follows: 85 clinical trials, 68 randomised controlled trials, 23 meta-analyses, 114 reviews. Guidelines and reviwes were discarded. Among clinical trials, we took into consideration those that were performed following a randomisation design and those which included a representative number of patients $(>200)$. With these restrictions, only 16 papers could be taken into consideration (table 1).

\section{Varenicline and considered studies outcomes}

Tsukahara et al conducted the first randomised controlled open comparative trial of varenicline vs nicotine patch in adult smokers in Japan, evaluating efficacy, safety and withdrawal symptoms in the 2 groups. The primary endpoint of this trial was the incidence of smoking cessation in the 2 groups at weeks 9-12 and weeks 9-24, and the safety and withdrawal symptoms, including stress, at weeks 12.

Reports of no smoking at week 12 were confirmed by measuring the end-expiratory $\mathrm{CO}$ concentration, using a cut off value of $8 \mathrm{ppm}$. Withdrawal symptoms were assessed using the Minnesota Nicotine Withdrawal Scale (MNWS), which contains 9 items, while stress was evaluated using self-monitoring questionnaires, the Stress Check List (SCL: 30 items), and the State-Trait Anxiety Inventory (STAI: A-Trait and A-State). This trial concluded that the continuous abstinence rates at weeks 9-12 and 9-24 were almost equal in both groups, heavy smokers quit smoking at only a low frequency and with tolerable adverse effects, which means that the choice of drugs should depend on the patient's request [32].

The multi-center, randomised, double-blind, placebo-controlled trial by Rigotti et al was conducted to test the efficacy of varenicline for smoking cessation in patients with stable car-diovascular disease. Also in this case the primary outcome was the 4-week continuous abstinence rate (CAR) during the last 4 weeks of study drug treatment (weeks 9 to 12), confirmed by the measurement of exhaled CO (upper limit 10 ppm). The secondary endpoints, besides drug safety, were particularly focused on cardiovascular adverse effects and mortality, CAR from week 9 through 52, for weeks 9 to 24 and 7-day point prevalence of tobacco abstinence at weeks 12, 24, and 52.

The trial has also provided an opportunity to observe any occurrence of psychiatric adverse events (AEs) that have been reported in the post marketing of varenicline, in particular cases of abnormal behaviour, depression, suicidal ideation, and suicide. As expected, varenicline demonstrated its superiority versus placebo in smoking cessation, was well tolerated and was not associated with increases in cardiovascular events, deaths, blood pressure, or heart rate in patients with history of cardiovascular diseases. Also rates of psychiatric AEs, were low and similar in the varenicline and placebo groups [33].

A very interesting paper by Tashkin, Rennard et al [34] studies the effects of varenicline versus placebo in smokers with mild to moderate COPD defined as the proportion of participants who reported no smoking or use of any nicotine containing products, with smoking abstinence confirmed by exhaled $\mathrm{CO}<10 \mathrm{ppm}$. The secondary efficacy end point was CO-confirmed CAR for weeks 9 to 52, CAR for weeks 9 to 24 and 7-day point prevalence of abstinence (self-reported abstinence from smoking during the preceding 7 days at each visit confirmed by CO measures) at weeks 12,24 , and 52 . In a separate analysis the authors also considered the pulmonary function testing, in terms of Forced Expiratory Volume in the 1st second $\left(\mathrm{FEV}_{1}\right)$, Forced Vital Capacity (FVC), $\mathrm{FEV}_{1} / \mathrm{FVC}$ ratio, Forced Expiratory Flow rate at $25 \%$ to $75 \%$ of the FVC and Peak Expiratory Flow rate (PEF), but tis data has not been published yet. This trial has shown that varenicline demonstrated superior efficacy compared with placebo among smokers with mild to moderate COPD, with prolonged time of smoking abstinence both at the end of treatment and over the subsequent year-long follow-up. In the Norwegian double blind, placebo controlled, randomised, multicentre, parallel group clinical trial by Fagerstrom et al [36] the primary efficacy end point was the CAR over the last four weeks of study treatment (weeks 9-12), defined as cotinine measurements during clinic visits. Secondary end points included long term continuous abstinence rate (weeks 9-26), seven day point prevalence of abstinence (defined as the proportion of participants who abstained from smokeless tobacco for the seven days before the end of treatment (week 12) and the end of the study (week 26)), and the safety and tolerability of varenicline versus placebo for 12 weeks of treatment. The limitation of this study can be the fact that salivary cotinine measurement in smokeless tobacco users might not reflect the same relation to nicotine metabolism in smokers, because some nicotine is swallowed, undergoes presystemic metabolism in the liver, and is immediately converted to cotinine. Furthermore, cotinine concentrations and Fagerstrom test scores did not predict outcomes, which is contrary to findings in the smoking cessation literature.

Mitchell Nides et al conducted a randomised, multicenter, double-blind, parallel-group, placeboand active-controlled phase 2 clinical trial of the efficacy and safety of varenicline in smoking cessation in a population of healthy smokers. The primary efficacy measure was the continuous quit rate $(\mathrm{CQR})$ for any 4 weeks, defined as abstinence 
Table 1. - Primary and secondary outcomes evaluated in varenicline studies

\begin{tabular}{|c|c|c|}
\hline Authors & Primary outcome & Secondary outcomes \\
\hline Tsukahara $\mathrm{H}$ et al [32] & 12- and 24-week CO-confirmed CAR & $\begin{array}{l}\text { - Safety } \\
\text { - Stress and anxiety at weeks } 12 \text { evaluated with SCL, } \\
\text { STAI and MNWS }\end{array}$ \\
\hline Rigotti NA et al [33] & $\begin{array}{l}\text { CO-confirmed CAR for weeks } 9 \text { to } 12 \\
\text { (last } 4 \text { weeks of treatment) }\end{array}$ & $\begin{array}{l}\text { - CAR from week } 9 \text { through } 52 \\
\text { - CAR for weeks } 9 \text { to } 24 \\
\text { - } 7 \text {-d point prevalence of tobacco abstinence at weeks } \\
12,24 \text {, and } 52\end{array}$ \\
\hline Tashkin DP et al [34] & CO-confirmed CAR for weeks 9 to 12 & $\begin{array}{l}\text { - CO-confirmed CAR for weeks } 9 \text { to } 52 \\
\text { - CAR for weeks } 9 \text { to } 24 \\
\text { - } 7 \text {-day point prevalence of abstinence (self-reported } \\
\text { abstinence from smoking during the preceding } 7 \text { days at } \\
\text { each visit confirmed by CO measures) at weeks } 12,24 \text {, } \\
\text { and } 52 \\
\text { - Pulmonary function tests }\end{array}$ \\
\hline
\end{tabular}

Lough LO et al [35] Smoking abstinence confirmed

with exhaled carbon monoxide $(\mathrm{CO})$

Fagerstrom K et al [36] 4- weeks CAR at weeks 9-12 confirmed with cotinine concentration

- CAR for weeks 9-26

- Seven day point prevalence of abstinence at week 12 and 26

- Safety and tolerability of varenicline versus placebo for 12 weeks of treatment

\begin{tabular}{|c|c|c|}
\hline Nides M et al [37] & 4-week CO-confirmed CAR at week 7 & $\begin{array}{l}\text { - CO-confirmed 4-week CAR for weeks } 4 \text { to 7, and at } 12 \text {, } \\
\text { 24, and } 52 \text { weeks } \\
\text { - Adverse event } \\
\text { - Modification in the MNWS and QSU-Brief questionnaires }\end{array}$ \\
\hline Oncken C et al [38] & $\begin{array}{l}4 \text { weeks CO-confirmed CAR for weeks } \\
4-7,9-12 \text { and } 9-52\end{array}$ & $\begin{array}{l}\text { - CO-confirmed 7-day point prevalence abstinence } \\
\text { - Changes in the MNWS and the mCEQ } \\
\text { - CO-confirmed 7-d point prevalence abstinence at weeks } \\
24 \text { and } 52\end{array}$ \\
\hline Douglas E et al [39] & 4 weeks CAR for weeks $9-12$ & $\begin{array}{l}\text { - } 4 \text { weeks CAR during the follow-up period (weeks 9-24 } \\
\text { and 9-52) }\end{array}$ \\
\hline Gary E et al [40] & 7- and 30-day point prevalent abstinence & \\
\hline Rennard S et al [41] & CO-confirmed CAR during weeks 9-12 & $\begin{array}{l}\text { - CAR during weeks 9-24 } \\
\text { - 7-day point prevalence of abstinence at Weeks } 12 \text { and } 24 \\
\text { - Time to first quit attempt }\end{array}$ \\
\hline Moore JT et al [42] & $\begin{array}{l}\text { Suicidal/self-injurious behavior or } \\
\text { depression defined as a case with SMQ }\end{array}$ & \\
\hline Dhelaria K et al [43] & Smoking status at 52 weeks & $\begin{array}{l}\text { - Follow up visits } \\
\text { - Behavioural counselling } \\
\text { - Side effects }\end{array}$ \\
\hline Boudrez H et al [44] & $\begin{array}{l}\text { CAR in the } 7 \text { days between week } \\
11 \text { and } 12 \text { based on verbal reporting }\end{array}$ & - Safety profile \\
\hline Fagerstrom et al [45] & CAR for 9-24 weeks & $\begin{array}{l}\text { - Fagerstrom test for nicotine dependence } \\
\text { - Modifications in HIS }\end{array}$ \\
\hline Aubin HJ et al [46] & $\begin{array}{l}4 \text { weeks exhaled } \mathrm{CO} \text { and self-reported } \\
\text { CAR from weeks } 9 \text { to } 12\end{array}$ & $\begin{array}{l}\text { - } 4 \text { weeks CAR through weeks } 24 \text { and } 52 \\
\text { - } 7 \text {-day point prevalence of abstinence at the end of treatment } \\
\text { and at the week } 24 \text { and week } 52 \text { visits } \\
\text { - Measures of craving (MNWS, mCEQ) } \\
\text { - Safety }\end{array}$ \\
\hline P. Wu et al [47] & Smoking cessation at 1 year & $\begin{array}{l}\text { - Short-term smoking cessation ( } \sim 3 \text { months) } \\
\text { - Adverse events }\end{array}$ \\
\hline
\end{tabular}

$\mathrm{CO}=$ carbon monoxide; $\mathrm{CAR}=$ continuous abstinence rate; MNSW = Minnesota Nicotine Withdrawal Scale; $\mathrm{SCL}=\mathrm{Stress}$ Check List of 30 items; STAI = State-Trait Anxiety Inventory; SMQ = Standardized MedDRA Query; QSU-Brief = Brief Questionnaire of Smoking Urges; mCEQ = Cigarette Evaluation Questionnaire. 
for any consecutive 28-day period during the treatment phase (determined by diary data). Secondary efficacy measures included the CO-confirmed ( $<10$ ppm) 4-week CQR for weeks 4 to 7 , as well as CQRs from week 4 to weeks 12, 24, and 52. The Authors concluded that varenicline has better short-term and long-term efficacy vs placebo and a good profile of safety [41].

Oncken et al [38] conducted a multicenter, double-blind, placebo controlled study randomising healthy smokers to assess the efficacy of varenicline in smoking cessation. The primary efficacy measures were the $\mathrm{CO}$-confirmed $(10 \mathrm{ppm}$ or lower) 4-week continuous quit rates by pooled dosage group for weeks 4 through 7 and 9 through 12 and the CAR for weeks 9 through 52. Secondary efficacy end points during the treatment period included the CO-confirmed 7-day point prevalence abstinence (abstaining from smoking during the preceding 7 days) and changes in the MNWS and the modified Cigarette Evaluation Questionnaire (mCEQ) by treatment group. Secondary long-term outcomes also included the COconfirmed 7-day point prevalence abstinence at weeks 24 and 52. In this case too varenicline showed its superiority versus placebo, even if the percentages of nausea experienced among the treated group varied from 16 to $42 \%$.

More or less the same primary outcome were took in consideration by Rennard et al [41], Jorenby et al [39] and Aubin et al [46] in their trials which investigated varenicline's efficacy and safety and compared it respectively with placebo, sustained release bupropion and nicotine transdermal patch.

The study by Swan et al [40] compared the effectiveness of three modalities of a behavioural smoking cessation program in smokers using varenicline: web-based counseling, proactive telephone-based counseling, or combined telephone and web counselling. Self-report determined the primary outcomes (7-day point prevalent abstinence at 3- and 6-month follow-up). This study reveals two important issues in nicotine addiction treatment. First, that there were no differences in abstinence outcomes at 6 months suggests that any of the three programmes offered here hold promise as alternative interventions in combination with varenicline. Second, this study provides important data regarding the use of varenicline in real-world settings and is responsive to the need for community-based trials involving varenicline. Use of varenicline in a real-world setting, with less stringent eligibility criteria and less clinical follow up than in the Phase III trials, still results in substantial abstinence outcomes when paired with behavioural intervention.

Moore's study aim [42] was to assess the rate of suicidal behaviour and depression in smoking cessation treatments. In particular bupropion and varenicline were analysed and the study shows a substantial, statistically significant increased risk for varenicline of reported depression and suicidal/self-injurious behavior. Bupropion for smoking cessation had instead smaller increased risks.
The study by Dhelaria et al [43] is a retrospective cohort study, comparing the effectiveness of varenicline with nicotine replacement therapy at one year. The primary endpoint was the smoking status at 52 weeks, than secondary endpoints included follow up visits, behavioural counselling and side effects. The message of the study is in contradiction with others clinical trials, because the authors affirm that varenicline and nicotine replacement were equally effective for smoking cessation and varenicline effectiveness is lower than reported in other clinical trials. Moreover behavioural therapy was rarely proscribed, but is very effective.

\section{Discussion}

Almost all articles we considered have abstinence from cigarettes at 9-12 weeks of treatment with varenicline as primary endpoint. Only one study considers changes in lung function measured with spirometry as a secondary endpoint (table 1). It should be noted from the data reported in table 1 that often the time lag considered to assess the permanent smoking cessation varies from study to study. A certain inhomogeneity between long and short observation periods can be found throughout the trials taken in account.

Another important aspect is the assessment method of smoking cessation; two are the possible approaches: the measure of urinary or salivary cotinite, which allows to discriminate between active and secondhand smoking, and the non-invasive measurement of exhaled CO. Some authors claim that an exhaled $\mathrm{CO}$ cut off of $8 \mathrm{ppm}$ [32] identifies only the $80 \%$ of actual smokers [48], thus appearing to have insufficient sensibility. Chatkin et al, on the other hand, have shown that the cut off value for exhaled $\mathrm{CO}$ of $10 \mathrm{ppm}$ could not be appropriate for smoking confirmation in patients with chronic obstructive pulmonary disease (COPD) with a $\mathrm{FEV}_{1}<50 \%$; this because it is possible that the degree of bronchial obstruction has interfered in the measure of the exhaled CO [49].

Only Fagerstrom used urinary cotinine to evaluate the smoking state of the subjects studied and he found no correlation between the cotinine concentrations and Fagerstrom test scores. These results appeared to contrast with the findings in smoking cessation literature $[53,54,36]$. A possible explanation of this fact could be that salivary cotinine measurement in smokeless tobacco users might not reflect the same relation with nicotine metabolism present in cigarette smokers, as some nicotine is swallowed, undergoes first pass metabolism in the liver, and is immediately converted to cotinine [36].

Surely, having an objective parameter to follow as a confirmation technique for cigarette withdrawal is mandatory. The patient report alone is not enough to elaborate a secure and reliable report on smoking cessation. The monitoring methods should be standardized and the measures at different timings should become the primary outcome in an efficacy-centered varenicline trial. 
Only one study considered changes in lung function measured with spirometry as a secondary endpoint [34]. The study population in this case was composed by mild and moderate COPD patients. It is known from numerous studies $[50,51]$ that the cessation of smoking habit correlates with a reduction in the rate of decline in lung function connected both to cigarettes smoking as to the age. Thus, the evaluation of lung function changes, not only considering spirometric-related volumes as $\mathrm{FEV}_{1}$, Inspiratory Capacity (IC) or Vital Capacity (VC), but also a more complete functional frame comprehending for example Specific AirWay Resistance (sRAW), should be assessed, in order to have a global physiopathological picture of the patient. However, these part of the results of the paper by Tashkin and Rennard have not been published yet [34].

If we consider the secondary endpoints, the profile of varenicline tolerability is an aspect which was often evaluated. In particular, the medication has shown a good profile of safety and efficacy, though in some categories of patients, such as those with active psychiatric diseases, there were cases of psychosis [52]. Maybe this particular aspect should be more investigated creating safety-based trials with primary outcomes designed especially to focus on the psychiatric side effects.

The modifications in the score of some frequently used questionnaires were used in many papers to demonstrate presence of withdrawal symptoms: Fagerstrom test for nicotine dependence, Heaviness of Smoking Index (HSI) [45], the Minnesota Nicotine Withdrawal Scale (MNWS) [32, $38,46,37]$, the modified Cigarette Evaluation Questionnaire (mCEQ) [38, 46]. In all these studies varenicline has proved its capability in reducing the scores in parallel with smoking cessation.

A parameter which is missing in all studies and in our opinion of fundamental importance in the evaluation of the cessation of smoking is lung function. It is in fact known that the cessation of smoking causes a lag of the speed of reduction in lung function and this is of fundamental importance especially for pneumologists and for patients affected of COPD.

This marker could be very important also as a way to evaluate, objectively, an improvement in lung function, which correlates also with subjective parameters, as dyspnea and fatigue. Other studies are required to investigate these important aspects in this complex field of smoking cessation for the care and welfare of the patient with respiratory disease.

\section{References}

1. World Health Organization. WHO report on the global tobacco epidemic. 2008 Geneva, Switzerland.

2. Patel DR, Feucht C, Reid L, Patel ND. Pharmacologic agents for smoking cessation: a clinical review. $\mathrm{Cl}$ Pharm Adv and Applic 2010; 2: 17-29.

3. Centers for Disease Control and Prevention: Smoking and tobacco use: fact sheets. [http://www.cdc.gov/tobacco/ data_statistics/ fact_sheets].
4. Santus P, Picciolo S, Proietto A, et al. General practitioners and management of patients with respiratory diseases in a real life survey. Panminerva Med 2012; 54: 293-298.

5. Hatsukami DK, Stead LF, Gupta PC. Tobacco addiction. Lancet 2008; 371 (9629): 2027-2038.

6. Aubry M, Wright JL, Myers JL. The pathology of smoking-related diseases. Clin Chest Med 2000; 21: 11-35.

7. Fiore MC, Piaseck TH, Baker LJ, Decren SM. Cigarette smoking: the leading preventable cause of pulmonary disease. Pulm Crit Care Med Bone RC, editors St. Louis, Mosby MO: 1998.

8. Patel DR, Homnick DN. Pulmonary effects of smoking. Adolesc Med 2000; 11: 547-565.

9. Sethi JM, Rochester CL. Smoking and chronic obstructive pulmonary disease. Clin Chest Med 2000; 21: 67-86.

10. US Department of Health and Human Services. The health consequences of smoking: a report of the surgeon general. 2004 Atlanta, GA: US Department of Health and Human Services, CDC, National Center for Chronic Disease Prevention and Health Promotion, Office of Smoking and Health [http://www.cdc.gov/tobacco/ data_statistics/sgr/sgr_2004/index.htm].

11. Takami T, Saito Y. Effects of smoking cessation on central blood pressure and arterial stiffness. Vasc Health Risk Manag 2011; 7: 633-638.

12. Rennard SI, Daughton D, Fujita J, et al. Short-term smoking cessation is associated with reduction in measures of lower respiratory tract inflammation in heavy smokers. Eur Resp J 1990; 3: 752-759.

13. Skold CM, Had J, Eklund A. Smoking cessation rapidly reduces cell recovery in bronchoalveolar lavage fluid while alveolar macrophage fluorescence remains high. Chest 1992; 101: 989-991.

14. Roos-Engstrand E, Ekstrand-Hammarström B, Pourazar $\mathrm{J}$, Behndig AF, Bucht A, Blomberg A. Influence of smoking cessation on airway $\mathrm{T}$ lymphocyte subsets in COPD. COPD 2009; 6: 112-120.

15. Karimi R, Tornling G, Grunewald J, Eklund A, Sköld $\mathrm{CM}$. Cell recovery in bronchoalveolar lavage fluid in smokers is dependent on cumulative smoking history. PLoS One 2012; 7: e34232.

16. FDA Consumer Health Information / U.S. Food and Drug Administration 2010.

17. Roddy E. Bupropion and other non-nicotine pharmacotherapies. BMJ 2004; 328 (7438): 509-511.

18. Hays JT, Ebbert JO, Sood A. Efficacy and safety of varenicline for smoking cessation. Am J Med 2008; 121 (4A): S32-S42.

19. Mottillo S, Filion KB, Bélisle P, et al. Behavioural interventions for smoking cessation: a metaanalysis of randomized controlled trials. Eur Heart J 2009; 30: 718-730.

20. Raupach T, Hoogsteder PH, Onno van Schayck CP. Nicotine vaccines to assist with smoking cessation current status of research. Drugs 2012, 72: e1-e16 00126667/12/0004-0001.

21. Wonnacott S, Sidhpura N, Balfour DJ. Nicotine: from molecular mechanisms to behaviour. Curr Opin Pharmacol 2005; 5: 53-59.

22. Tapper AR, McKinney SL, Nashmi R, et al. Nicotine activation of a4b2 receptors: sufficient for reward, tolerance, and sensitization. Science 2004; 306: 10291032.

23. Picciotto MR, Corrigall WA. Neuronal systems underlying behaviors related to nicotine addiction: neural circuits and molecular genetics. J Neurosci 2002; 22: 3338-3341.

24. Koob GF. Neural mechanisms of drug reinforcement. Ann N Y Acad Sci 1992; 654: 171-191.

25. Tzschentke TM. Pharmacology and behavioural pharmacology of the mesocortical dopamine system. Prog Neurobiol 2001; 63: 241-320. 
26. Coe JW, Brooks PR, Vetelino MG, et al. Varenicline: an 42 nicotinic receptor partial agonist for smoking cessation. J Med Chem 2005; 48: 3474-3477.

27. Rollema H, Chambers LK, Coe JW, et al. Pharmacological profile of the a4b2 nicotinic acetylcholine receptor partial agonist varenicline, an effective smoking cessation aid. Neuropharmacology 2007; 52: 985-994.

28. Tonstad S, Davies S, Flammer M, Russ C, Hughes J. Psychiatric adverse events in randomized, doubleblind, placebo-controlled clinical trials of varenicline: a pooled analysis. Drug Saf 2010; 33: 289-301.

29. Leung LK, Patafio FM, Rosser WW. Gastrointestinal adverse effects of varenicline at maintenance dose: a meta-analysis. BMC Clin Pharm 2011; 11: 15.

30. Singh S, Loke YK, Spangler JG, Furberg CD. Risk of serious adverse cardiovascular events associated with varenicline: a systematic review and meta-analysis CMAJ 2011; 183: 1359-1366.

31. Prochaska JJ, Hilton JF. Risk of cardiovascular serious adverse events associated with varenicline use for tobacco cessation: systematic review and meta-analysis BMJ 2012; 344: e2856.

32. Tsukahara H, Noda K, Saku K. A randomized controlled open comparative trial of varenicline vs nicotine patch in adult smokers - efficacy, safety and withdrawal symptoms. Circul J 2010; 74: 771-778.

33. Rigotti NA, Pipe AL, Benowitz NL, Arteaga C, Garza D. Efficacy and safety of varenicline for smoking cessation in patients with cardiovascular disease: a randomized trial. Circul 2010; 121: 221-229.

34. Tashkin DP, Rennard S, Hays JT, Ma W, Lawrence D, Lee TC. Effects of varenicline on smoking cessation in patients with mild to moderate COPD: a randomized controlled trial. Chest 2011; 139: 591-599.

35. Lough LE, Ebbert JO, McLeod TG. Evaluation of a student-run smoking cessation clinic for a medically underserved population. BMC Research Notes 2011; 4: 55.

36. Fagerström K, Gilljam H, Metcalfe M, Tonstad S, Messig M. Stopping smokeless tobacco with varenicline: randomised double blind placebo controlled trial. $B M J$ 2010; 341: c6549 doi:10.1136/bmj.c6549.

37. Nides M, Oncken C. Smoking cessation with varenicline, a selective nicotinic receptor partial agonist. Results from a 7-week, randomized, placebo- and bupropion-controlled trial with 1-year follow-up. Arch Intern Med 2006; 166: 1561-1568.

38. Oncken C, Gonzales D, Nides M. Efficacy and safety of the novel selective nicotinic acetylcholine receptor partial agonist, varenicline, for smoking cessation. Arch Inter Med 2006; 166: 1571-1577.

39. Jorenby DE, Hays JT, Rigotti NA. Efficacy of Varenicline, an a4b2 Nicotinic Acetylcholine Receptor Partial Agonist, vs Placebo or Sustained-Release Bupropion for Smoking Cessation A Randomized Controlled Trial. JAMA 2006; 296: 1.
40. Swan GE. Behavioral Counseling and Varenicline Treatment for Smoking Cessation. Am J Prev Med 2010; 38: 482-490.

41. Rennard S, Hughes J. A randomized placebo-controlled trial of varenicline for smoking cessation allowing flexible quit dates. Nic \& Tob Res 2012; 3: 343-350.

42. Moore TJ, Furberg CD, Glenmullen J, Maltsberger JT, Singh S. Suicidal behaviour and depression in smoking cessation treatments. PLoS ONE 2011; 11: e27016.

43. Dhelaria RK, Friderici J, Wu K, Gupta E, Khan C, Rothberg MB. Effectiveness of varenicline for smoking cessation at 2 urban academic health centers. Eur J Inter Med 2012; doi:10.1016/j.ejim.2012.03.017.

44. Boudrez H, Gratziou C, Messig M, Metcalfe M. Effectiveness of varenicline as an aid to smoking cessation: results of an inter-European observational study. Curr Med Res Opin 2011; 27: 769-775.

45. Fagerström K, Russ C, Yu CR, Yunis C, Foulds J. The fagerstrom test for nicotine dependence as a predictor of smoking abstinence: a pooled analysis of varenicline clinical trial data. Nicotine Tob Res 2012; 14: 1467-1473.

46. Aubin HJ, Bobak A, Britton JR, et al. Varenicline versus transdermal nicotine patch for smoking cessation: results from a randomised open label trial. Thorax 2008; 63: 717-724.

47. Ping W, Kumanan W, Popey D, Edward JM. Effectiveness of smoking cessation therapies: a systematic review and meta-analysis. BMC Public Health 2006; 6: 300.

48. Pearce MS, Hayes L. Self-reported smoking status and exhaled carbon monoxide: results from two populations-based epidemiologic studies in the North England. Chest 2005; 128: 1233-1238.

49. Chatkin JM, Abreu CM, Blanco DC. Exhaled carbon monoxide as a marker of tobacco exposure: is it possible to use the same parameters in COPD patients? Proceedings of the $16^{\text {th }}$ Congress of the European Respiratory Society: P2305.

50. Fletcher C, Peto R. The natural history of chronic airflow obstruction. $B M J$ 1977; 1: 1645.

51. Young RP, Hopkins R, Eaton TE. Forced expiratory volume in one second: not just a lung function test but a marker of premature death from all causes. Eur Respir $J$ 2007; 30: 616-622.

52. Gupta A, Bastiampillai T, Adams M, Nelson A, Nance M. Varenicline induced psychosis in schizophrenia. Aust N Z J Psychiatry 2012; 11.

53. Ferguson JA, Patten CA, Schroeder DR, Offord KP, Eberman KM, Hurt RD. Predictors of 6-month tobacco abstinence among 1224 cigarette smokers treated for nicotine dependence. Addict Behav 2003; 28: 1203-1218.

54. Harris KJ, Okuyemi KS, Catley D, MayoMS, Ge B, Ahluwalia JS. Predictors of smoking cessation among African-Americans enrolled in a randomized controlled trial of bupropion. Prev Med 2004; 38: 498-502.

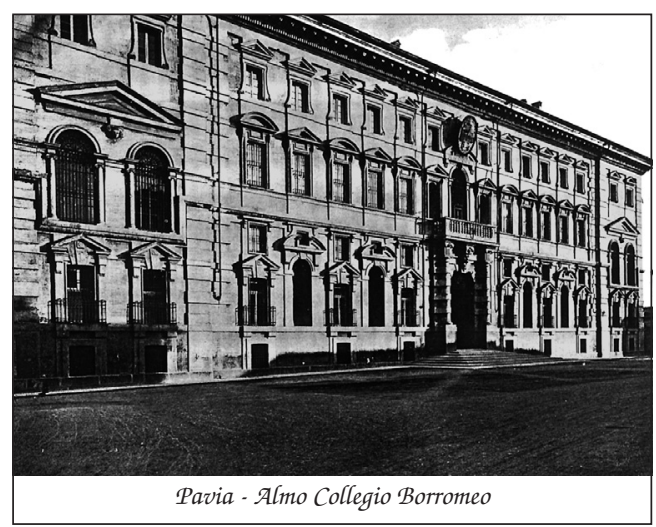

